\title{
Mulberry and its waste utilization an important socio-economic status in sericulture
}

\author{
Y.T. Jadhav*, B. Kiran Kumar Babu, A.D. Chavan and K.N. Tambave
}

Department of Agricultural Entomology, Ratnai College of Agriculture, Akluj (M.S.) India

\section{ARITCLE INFO}

Received : 17.02 .2020

Accepted : 28.03 .2020

\section{KEY WORDS :}

Mulberry, Wastes, Importance, Socioeconomic, Sericulture
*Corresponding author:

Email : rupayogeshjadhav@gmail.com

\begin{abstract}
Mulberry plant is an extremely versatile plant that can fulfill a number of roles in smallholder agricultural production. Mulberry has been used as silkworm feed also in traditional oriental medicine as a anti-oxidative, anti-inflammatory, anti-cancer, antidiabetic, anti-obesity and also to treat cardiovascular problems. Mulberry fruits are used as a foodstuff to enhance the cattle milk production. Mulberry stem and root barks can be used in the paper making industry. Dried wastes of mulberry are utilized in poultry rations which improve the nutritional content i.e., vitamin A, finally increasing their egg production. Mulberry wastes such as stem, leaves, branches etc. are used in biofuel and biogas production which can inflates a notable avenue to seri-farmers. Its high thickness stems are applied in manufacturing of hockey sticks and various agricultural implements. Their biomass waste is an valuable raw material for the pharmaceutical industry due to its high flavones and phenol content. Hence whole mulberry plant have a specific value and if proper utilization of such raw material takes place it can open new vista in industrial exploitation which may help to uplift standard of living and socio- economic status of seri-farmers.
\end{abstract}

How to view point the article : Jadhav, Y.T., Kiran Kumar Babu, B., Chavan, A.D. and Tambave, K.N. (2020). Mulberry and its waste utilization an important socio-economic status in sericulture. Internat. J. Plant Protec., 13(1) : 119-124, DOI : 10.15740/HAS/IJPP/13.1/119-124, Copyright@ 2020: Hind Agri-Horticultural Society. 